G. P. Murdoch, of Yale, outlined the anthropological studies in Micronesia. Papers on dental caries, tuberculosis and tropical diseases, together with reports on remedial measures, were contributed, and further research programmes were discussed. These sessions covered a wide and important field on medical and social problems, and represented a very live and vigorous section of the Congress. The present writer presided at a general Congress discussion on the "Social Implications of Science".

Parties of overseas delegates in groups of some twenty members were taken on conducted tours each of a week's duration through the North and South Islands. These tours were arranged to bring delegates south from Auckland to Christchurch with stops at interesting centres en route, and also after the termination of the Christchurch sessions. Apart from the scenic interest of these excursions by road, the delegates gained, by scientific intercourse and social fellowship, a lasting benefit comparable with, or even exceeding, that of the organised Congress itself.

In conclusion, it is a pleasant duty to acknowledge the help I have received from my fellow delegates from Britain in compiling this report, namely, Prof. G. W. Robinson, the leader; Sir Geoffrey Taylor; Prof. H. D. Kay; Prof. C. M. Yonge; Dr. G. E. R. Deacon and Dr. R. A. Silow, whose impressions, together with my own, I have endeavoured to record. These can, however, reflect only a small part of the whole work of the Congress.

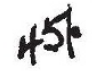

PRE-STRESSED CONCRETE
$\mathrm{N}$ recent years yore has been a growing interest among engiffers in the use of pre-stressing for concrete strictures, apd on February 16 a conference was hell at he Institution of Civil Engineers to review he present position of pre-stressed concrete. The conference was arranged under the auspices of th 1 stitution and the Joint Committee on Materials and their Testing (a Committee representing some twenty-five technical and professional institutions and societies). The chair was taken, for the morning session, by Mr. R. H. H. Stanger, and, for the afternoon session, by Mr. W. K. Wallace.

A paper by Dr. F. G. Thomas, of the Building Research Station, had been prepared as a basis for discussion. The basic principle of pre-stressing, Dr. Thomas pointed out, consists in the imposition of preliminary internal stresses in a structure before the working loads are applied, in such a way as to lead to a more favourable state of stress when these loads come into action. The preliminary stresses induced in concrete are essentially pre-compressions, which may be uniform or non-uniform, with the primary object of avoiding cracking under the conditions of working load. In most practical cases the pre-stress is applied by stretched steel wires of high tensile strength.

A description of the early development of the technique was followed in the paper by a comprehensive survey of the basic features of prestressed concrete, including the materials used, the fundamental assumptions to be made in design and the various practical systems of pre-stressing. Dr. Thomas gave a brief account of the experimental investigations that have been made, and concluded with descriptions of constructional work executed in
Great Britain and elsewhere. This section of the paper embraced references to bridges, tanks, reservoirs and pipes, buildings, and miscellaneous work such as tunnels, harbour construction, aeroplane runways and railway sleepers.

In introducing his paper, Dr. Thomas emphasized the need for high-quality materials to be used in pre-stressed concrete construction. Although a high strength of concrete is not always necessary, but often desirable, a high standard of quality control is essential. A high early strength of the concrete is required on economic grounds, and usually a rapidhardening cement is adopted or suitable accelerators are incorporated in the concrete mix; curing with steam or electric heating is also of value in regard to rapidity of hardening.

For most of the design calculations, Dr. Thomas pointed out, no new theory is necessary. The classic theory of elasticity is applicable if approximate allowances are made for the effects of inelastic deformations due to creep (of steel and concrete) and to shrinkage of the concrete. There are two main systems of pre-stressing : the pre-tensioning system, in which the wires are stretched before the concrete has set; and the post-tensioning system, in which the wires are stretched after the concrete has hardened and obtained considerable strength. Whatever basic system of pre-stressing is adopted, there are many variations in the actual detailed arrangements. A study of the relative merits of the main processes has led Dr. Thomas to the conclusion that there is no general technical justification for one rather than another; the method to be chosen appears to depend upon technical and economic considerations relating to the particular circumstances of each design.

Referring to constructional work already completed, Dr. Thomas observed that the main advantages of pre-stressing have been obtained in beams and fluid-retaining structures. In the case of beams, the greatest advantages are reached where the effects of reduced sections and light weight are particularly important, that is, in bridges of larger span. In the case of fluid-retaining structures, where cracking must be avoided and where difficulty has been experienced in obtaining satisfactory joints in ordinary reinforced concrete, it seems certain that in the future a greater proportion of these structures will be made of pre-stressed concrete.

The possibility of using pre-stressing for roads or runways is of interest, particularly in view of the difficulty experienced in the past in obtaining good joints. In the Orly Airport runway, Freyssinet has experimented in this direction, and it may well be that pre-stressing will solve another difficult civilengineering problem.

In the discussion which followed the presentation of the introductory paper, several speakers emphasized the desirability of using high-grade materials. Mr. J. W. H. King (Queen Mary College, London) pointed out that metallurgical study shows that the hard-drawn wire commonly used for pre-stressing possesses certain properties as a result of the drawing process in manufacture (for example, creep under sustained load or deformation) which are detrimental to the efficiency of the wire as a pre-stressing agent, subject to high tensile stress for the whole life of the structure. Prof. R. H. Evans (University of Leeds) agreed with Dr. Thomas that with $0 \cdot 2$-in. diameter wire the margin of safety against wire slip, in systems dependent on the bond between concrete and steel, is often not sufficient. Tests at the University of Leeds 
have shown that, for the transfer of the pre-stressing load from the steel to concrete by surface interaction alone, a length of wire of $80-250$ diameters is necessary. Triple-stranded wires have been found to have better bond characteristics than single round wires. Mr. U. Bjuggren (Stockholm) remarked that in Sweden small-diameter $(0 \cdot 08$-in.) wires are used in pre-tensioning systems; up to 140 wires have been used in a relatively small cross-section, and satisfactory bond has been obtained.

In regard to the concrete quality, Dr. A. R. Collins (Cement and Concrete Association) spoke of the simplicity of the arrangement of steel in pre-stressed concrete, contrasting this with the conglomeration of reinforcement in ordinary reinforced concrete. The simplicity is coupled with a greatly reduced amount of steel and allows the use of a concrete of relatively low workability and high durability. Concrete of high strength is not difficult to obtain if adequate control is exercised in the measurement and proportioning of the materials, and if the water content is limited to the minimum necessary for proper compaction of the concrete.

Mr. R. S. V. Barber (Dow-Mac (Products), Ltd.) and Mr. J. Ludlow (Metropolitan-Vickers Electrical Co., Ltd.) described work on electric heating as a method of accelerating the hardening of concrete, pointing out that electric heating can be arranged with the electric current passing through the concrete or alternatively through the reinforcing wires. The former has been used as a conductor, particularly in the U.S.S.R., to avoid frost action during the early hardening of the concrete, but a high current-density may affect the proper hydration of the cement. Mr. Barber and Mr. Ludlow said that they have therefore used the alternative method, namely, of heating the embedded wires, in the production of concrete railway-sleepers. This method has the advantages that the electrical resistance of the steel is constant, stable and small. The arrangement of straight wires in the pre-tensioning system is ideal for this treat ment, which has resulted in a reduction in the production eycle from five to one day or even less.

On the fundamental approach to the design of pre-stressed concrete members there was some divergence of opinion. Prof. A. L. L. Baker (University of London) presented an analytical method for the determination of the ultimate strength of a prestressed concrete beam, and Prof. A. D. Ross (University of London) discussed the accurate assessment of losses of pre-stress due to inelastic deform. ation of the concrete. Other speakers were in favour of simple approximations for these losses; and Mr. Bjuggren (Stockholm) relied for his designs on empirical rules based on hundreds of tests.

The application of pre-stressed concrete to various structural systems was discussed by several speakers. Major A. J. Harris (Société Technique pour l'Utilisation de la Précontrainte, Paris), representing M. E. Freyssinet, showed how the difficulties of obtaining structurally continuous systems have been overcome in France. In statically indeterminate systems, pre-stressing tends to modify the supporting reactions for beams, involving an elaboration of the design calculations, and it also introduces practical difficulties. M. Freyssinet has devised a system of beams of variable cross-section, pre-stressed by straight cables, which has largely obviated the difficulties. In an alternative solution, the reactions are adjusted in practice to the values assumed in design, by introducing special small flat jacks. Major Harris also described the construction of bridges from pre-fabricated units. Elements $6 \mathrm{ft}$. long, cast in a factory, are later assembled to form a 240-ft. span bridge, the elements being held together by pre-stressing cables.

Mr. N. W. Swinnerton (British Railways) described the development of pre-stressed concrete railway. sleepers in Great Britain, involving laboratory tests and trials in high-speed track, leading to two designs which show promise. Mr. J. S. Campbell and Dr. P. W. Abeles (British Railways) spoke of successful bridge eonstruction already completed in Great Britain and of further work soon to be started. In this latter connexion, Dr. Abeles discussed designs in which pre-stressed units would be combined with in situ concrete without preliminary stress, and gave details of tests showing that such composite construction is practicable and amenable to accurate stress analysis.

Mr. L. W. Elliott put forward the architect's point of view on pre-stressed concrete. The three essential considerations are the resthetic, the functional and the economic aspects. The practical examples have shown that resthetic and functional requirements can be well satisfied, and it appears that this type of construction is also economical. Mr. D. H. May (Stressed Concrete Design, Ltd.) discussed the economical aspect further, and gave evidence of cases in which pre-stressed concrete has been chosen, in direct competition with steel and reinforced concrete, for several structures in Europe and in America.

The proceedings of the conference are to be nublished later this year.

\section{NEW FELLOWS OF THE ROYAL SOCIETY}

A $\mathrm{T}$ the meeting of the Royal Society on March 17, A the following were elected to fellowship :

Prof. J. F Allen, professor of natural philosophy, University of St. Andrews, distinguished for his work in low-temperature physics, especially for his discovery of new phenomena shown by liquid helium.

R. W. Bailey, head of the Mechanical and Metallurgical Research Department at MetropolitanVickers, Manchester, distinguished for contributions on the behaviour of metals at high temperatures and for advances in design of turbines.

Dr. F. C. Bawden, head of the Plant Pathology Department at Rothamsted Experimental Station, Harpenden, distinguished for his work on plant viruses and virus diseases, and for important contributions to the study of virus serology.

Prof. F. W. Rogers Brambell, Lloyd Roberts professor of zoology, University College of North Wales, Bangor, distinguished for his experimental studies of processes of reproduction in mammals and of the factors concerned in antenatal mortality.

Prof. K. E. Bullen, professor of applied mathematics in the University of Sydney, distinguished for work in geophysics, particularly in relation to earth. quakes and the distribution of density within the earth.

Dr. E. B. Chain, university demonstrator in chemical pathology, University of Oxford, distinguished for his work on enzymes of snake-venom and bacteria, and especially for his researches on penicillin and other antibiotics. 